Article

\title{
Power Plant Optimisation-Effective Use of the Nelder-Mead Approach
}

\author{
Paweł Niegodajew ${ }^{\mathbb{D}}$, Maciej Marek*므, Witold Elsner ${ }^{\mathbb{D}}$ and Łukasz Kowalczyk \\ Department of Thermal Machinery al., Czestochowa University of Technology, Armii Krajowej 21, \\ 42-200 Czestochowa, Poland; niegodajew@imc.pcz.czest.pl (P.N.); welsner@imc.pcz.czest.pl (W.E.); \\ kowalczyk_l@wp.pl (Ł.K.) \\ * Correspondence: marekm@imc.pcz.czest.pl
}

Received: 29 January 2020; Accepted: 13 March 2020; Published: 20 March 2020

\begin{abstract}
This paper demonstrates the use of a combined software package including IPSEpro and MATLAB in the optimisation of a modern thermal cycle. A $900 \mathrm{MW}$ power plant unit (operating at ultra-supercritical conditions) was considered as the study object. The Nelder-Mead simplex-based, direct search method was used to increase power plant efficiency and to find the optimal thermal cycle configuration. As the literature reveals, the Nelder-Mead approach is very sensitive to the simplex size and to the choice of method coefficients, i.e., reflection, expansion and contraction. When these coefficients are improperly chosen, the finding of the optimal solution cannot be guaranteed, particularly in such complex systems as thermal cycles. Hence, the main goal of the present work was to demonstrate the capability of an integrated software package including IPSEpro, MATLAB and MS Excel in the optimisation process of a complex thermal cycle, as well as to examine the effectiveness of the most popular sets of Nelder-Mead coefficients previously proposed by other researchers. For the investigation purposes, the bleed and outlet pressures from the turbines were considered as decision variables, and the power plant efficiency was used as an objective function.
\end{abstract}

Keywords: Nelder-Mead; gradient free optimisation; direct search; simplex search; thermal cycle; advanced ultra-supercritical power plant

\section{Introduction}

During the last few decades, huge progress in energy production with the use of coal fired power plants (PP) has been observed. Such improvements have been achieved by increasing live steam parameters, i.e., pressure and temperature. Standard subcritical power plants operating with live steam temperatures of up to $550{ }^{\circ} \mathrm{C}$ and pressures within the range between 16 and $17 \mathrm{MPa}$ have allowed for electricity conversion with an efficiency of $38 \%$ [1], while the introduction of supercritical conditions, a steam temperature of $600{ }^{\circ} \mathrm{C}$ and a pressure of 22-24 MPa has allowed an increase in the PP efficiency up to $45 \%$ [2]. The further development of such technology towards even greater ultra-supercritical conditions, with steam temperatures of up to $650{ }^{\circ} \mathrm{C}$ and pressures even higher than $26 \mathrm{MPa}$ have allowed the generation of electricity with an efficiency approaching $50 \%[3,4]$.

Today, the power plant industry is still facing continued technology development aimed at introducing even greater live steam parameters, classified as advanced ultra-supercritical conditions (A-USC), with temperatures of $700 / 720^{\circ} \mathrm{C}$ and pressures of about $35 \mathrm{MPa}$, which should ensure the achievement of PP efficiencies even higher than 52\% [5].

The implementation of A-USC conditions extorts the development of subsequent PP elements-for example, new steam turbines [6,7] and high performance boilers [8] - and the implementation of alternative technical solutions, such as boilers equipped with fluidised beds [9-11]. An increase in live steam conditions cannot be achieved without intervening in the structure of a thermal cycle or 
without the changing of local parameters. As a consequence, a number of PP configurations have been introduced, i.e., those with a single reheat [12], those with a double reheat [13], those with a regenerative-also called tuning-turbine [14], and solutions utilising waste heat to improve PP efficiency [15]. The development of such technology also presents a number of challenges in the development of even more advanced combined gas-steam cycles $[16,17]$.

Currently, government regulations, especially in European countries, give attention to the reduction of greenhouse gasses, mainly of $\mathrm{CO}_{2}$. In turn, newly designed installations have been developed, such as integrated gasification combined cycle (IGCC) [18] and carbon capture units coupled with power plants [19], which enhance the complexity of thermal cycles' structures and make the finding of optimal working conditions a problematic issue.

Thus, the very complex structure of $\mathrm{PP}$, accompanied by a multitude of partial processes and a variety of thermal cycle variants, means that the development of efficient numerical tools allowing to search for the optimal configuration of each PP thermal cycle is strongly recommended. A promising solution may be the coupling of mathematical modelling together with optimisation algorithms. It should be noted, however, that the complex PP contains a considerable number of units, which makes the optimisation task exceptionally difficult.

The available literature offers a variety of optimisation heuristics, which can be generally classified into two groups, i.e., gradient-based and direct search (DS) approaches $[20,21]$. The former require the information concerning not only the objective function but also the gradient (partial derivatives). In this approach, the objective function must be differentiable within the entire computational domain [22]. DS optimisation methods search for the optimum solely based on the objective function. On the one hand, when the objective function can be easily differentiated, derivative-based approaches are much more effective than DS methods, as the convergence is reached much faster. On the other hand, in a number of practical applications, the estimation of the gradient may require substantial computational effort, consequently leading to a decrease in the efficiency of such method types. In turn, the application of DS approaches is usually more convenient [23].

Optimising a PP, which is very complex, and where non-linear interactions exist between parameters, it is essential to have the possibility of a flexible formulation of the optimisation task and the constraints. Today, many of commercially available software packages include their own optimisation tools. However, in most cases, the constraint function is given as an explicit formula, so the application of these tools in practice is strongly limited. Thus, as the source literature reveals, authors usually focus on the development of their own in-house algorithms [24-27].

A variety of strategies related to the optimisation of power plants can be found. The most frequently used are Genetic Algorithm (GA) [28,29] and the methods involving soft-computing [30,31]. Some works can be found also utilising other optimisation techniques such as Monte Carlo simulations [32], the sequential quadratic programming method [33], particle swarm optimisation [34,35], methods allowing the yielding of a set of Pareto frontiers, multi-objective optimisation [36] and the optimisation procedures available in the MATLAB Optimization Toolbox [37].

Only a few works are devoted to the application of DS methods in the optimisation of thermal cycles. For instance, in one work [38], a coupling between a complex mathematical model of a combined power plant and the Rosenbrock algorithm was performed to find the best thermal cycle configuration. In another work [39], the Nelder-Mead (NM) approach was used to optimise 900 MW PP working with A-UCS conditions. In one of the most recent papers [40], the usefulness of three different DS methods, i.e., NM, Rosenbrock and Hooke-Jeeves, in the optimisation of A-UCS PP was examined. The last work revealed a huge potential of these approaches in the optimisation of complex thermal cycles.

The present work was about numerical modelling and the DS optimisation of conceptual advanced ultra-supercritical (A-USC) PP with the use of a software package including IPSEpro and MATLAB. The NM simplex based algorithm was used for the optimisation purpose. The NM approach was selected due to several reasons: 
- It is a widely used DS method for solving the unconstrained optimisation problem and it is very easy to implement in practice [23,41],

- Its usefulness in the optimisation of A-USC PP has already been found, however, it was found that even when the position of the initial simplex is changed monotonously, the paths in the decision space can substantially change, leading to non-monotonous variations in computation time (CT) [40].

The latter reason constitutes the primary motivation for the present study, which is, concomitantly, the continuation of the work already undertaken in [40]. The sensitivity of the NM algorithm to the choice of initial points may noticeably influence the computing time, particularly when a large number of decision variables is concerned. Such inconvenience has already been recognised in a number of research works, and much effort has been put to finding the best solution for this problem. For instance, in the work [42], authors conducted a sensitivity study with the use of a selected set of test cases, which consequently allowed the determination of the best values of the NM coefficients leading to the largest number of successes in the minimisation procedure. Begambre and Laier [43] combined the Particle Swarm Optimisation with the NM simplex approach in order to utilise the benefits of each method, and developed a more stable hybrid approach. Wang and Shoup [44] continued the study already performed in [42] to better understand the NM parameters' impact on algorithm behaviour. The comprehensive parameter sensitivity study was performed using seven different mathematical functions. This test showed important relations between the NM Simplex parameters (i.e., reflection, expansion, contraction and simplex size) and the optimal solutions. Moreover, the authors proposed a different set of NM parameters than those pointed out in the work [42].

The major aim of the present work was to demonstrate the capability of software packages including IPSEpro, MATLAB and MS Excel in the optimisation process of a complex power plant, as well as to analyse the impact of three different NM configurations on the optimisation of A-USC PP. In particular, the original set of NM parameters was compared with the sets of coefficients proposed in works [42] and [44], collected in Table 1 and denoted further within the paper as setup 1, setup 2 and setup 3.

In order to introduce an additional novel element with respect to the work [40], the impact of different sets of decision variables-i.e., all of the bleed and outlet pressures from each turbine on the objective function (i.e., the PP efficiency)—was examined.

Table 1. A comparison of suggested Nelder-Mead (NM) coefficients.

\begin{tabular}{cccc}
\hline \multirow{2}{*}{ NM Coefficient } & Original NM & Fan and Zahara [42] & Wang and Shoup [44] \\
\cline { 2 - 4 } & Setup 1 & Setup 2 & Setup 3 \\
\hline reflection $(\alpha)$ & 1.00 & 1.50 & 1.29 \\
expansion $(\gamma)$ & 2.00 & 2.75 & 2.29 \\
contraction $(\beta)$ & 0.50 & 0.75 & 0.47 \\
simplex size $(\delta)$ & 0.50 & 0.50 & 0.57 \\
\hline
\end{tabular}

\section{Numerical Approach}

\subsection{A General Outline of the Computing Algorithm}

The optimisation task was carried out using a set of software packages including IPSEpro (which is a numerical tool suitable for the modelling of various types of thermal cycle [45-48]), MATLAB and MS Excel. This program is characterised by a modular structure, which allows for its modification, and in turn, development. The general block diagram describing the computing procedure is presented in Figure 1. The initial forms of adequate NM simplex matrices, regarding the number of decision variables, the objective function and algorithm parameters $(\alpha, \gamma, \beta$ and $\delta)$ are declared in MATLAB and sent to MS Excel, where, using the PSExcel data exchange module, they are further sent to the 
Process Simulation Environment (PSE). PS Excel and PSE are integrated parts of the IPSEPro software. The numerical calculation of the power plant is conducted in PSE, and the obtained results are sent back to MS Excel again via PSExcel and then can be read by MATLAB. Finally, the results can be used by NM to search for new values of decision variables, and afterwards, the whole processes repeats itself to the moment when the convergence criteria are satisfied, i.e., the difference of the value of the objective function is less than $\varepsilon=10^{-6}$ from one iteration to the next one. A detailed discussion about the selection of this criterion can be found in the previous work [40].

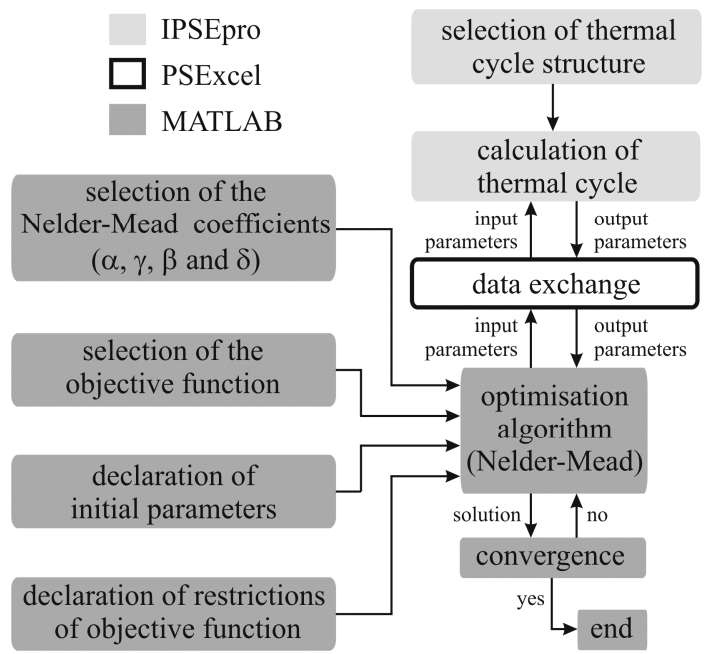

Figure 1. A scheme of the communication between IPSEpro, PSExcel and MATLAB.

\subsection{The Nelder-Mead Method}

The Nelder-Mead algorithm originally proposed in [49] is a widely accepted DS optimisation method that has found its usefulness in a number of unconstrained problems [50]. NM utilises the iterative procedure in order to produce a sequence of simplexes converging to the optimal solution [51]. The NM method requires $n+1$ vertices for the definition of the initial position of the simplex where the n-dimensional optimisation problem is concerned [52]. The following operations need to be performed within a single iteration to change the simplex shape: reflection, expansion, contraction and reduction [53]. These operations lead to the evolution of the simplex in the decision space, which eventually should converge to the optimum solution. However, depending on the initial position, shape and orientation of the initial simplex, this evolution may proceed in an unexpected manner, for instance, with less iterations for a larger number of decision variables [40]. The values of the NM coefficients for the main operations (reflection, expansion, contraction and reduction) are typically taken as $\alpha=1, \gamma=2, \beta=0.5$ and $\delta=0.5$, respectively. Here, these values were compared with two other sets of coefficients introduced in the work of Fan and Zahara [42], and Wang and Shoup [44] (presented in Table 1), who showed that the modification of the standard algorithm's coefficients results in better performance of the method. However, their investigation was limited to simple mathematical functions only.

As stated above, the NM method is usually applied in unconstrained problems; however, in the present study, lower bound constraints were considered for the selected variables due to the specific nature of the power plant. For this purpose, the algorithm was modified in a way to ensure that the value of a considered variable could not fall below the lower bound. Besides this exception, the NM algorithm proceeded in the typical way. 


\section{Object of the Research}

\subsection{PP Cycle Description}

In the present investigation, the A-UCS $900 \mathrm{MW}$ PP-schematically shown in Figure 2-is considered as the reference cycle. This PP has an unusual configuration as it contains an additional tuning turbine (T-T), based on the concept proposed in the work [54]. The application of the T-T turbine ensured a slightly greater PP efficiency in comparison with the cycle without this particular element. Such a solution has already been used as an object of research, for instance, in the A-USC PP coupled with the post-combustion capture installation [19]. The cycle of PP shown in Figure 2 includes key object components, including the boiler (B); the high pressure (HP), intermediate pressure (IP) and low pressure (LP) turbine sections; the T-T; the condenser; five preheaters of the low pressure regeneration system; the deaerator (DEA) and three preheaters of the high pressure regeneration system.

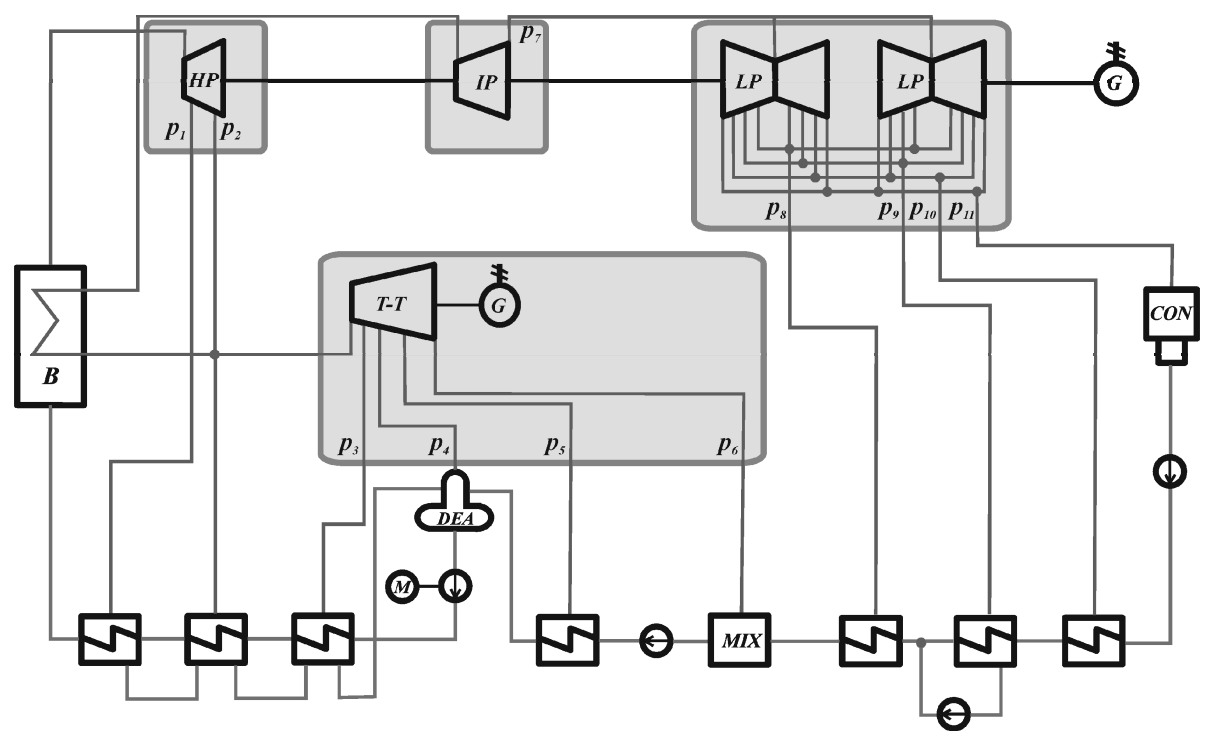

Figure 2. The general scheme of the power plant (PP) thermal cycle with the set of parameters used in optimisation.

The details about PP operating parameters used in the simulations are summarised in Table 2, whereas more information about the thermal cycle can be found in the works $[40,55]$. As the PP structure is very complex, the optimisation process was limited to the turbine sections-see the areas marked with the grey background in Figure 2. All of the bleed and outlet pressures from each turbine were considered as decision variables. The correctness of the selection of these parameters was confirmed by Aljundi [56], who indicated that around 13\% of the fuel exergy delivered to the PP cycle is lost in the turbine sections.

Table 2. The power plant operating parameters.

\begin{tabular}{cccc}
\hline Parameters & Value & Unit \\
\hline \multirow{2}{*}{ live steam parameters } & temperature & 700 & ${ }^{\circ} \mathrm{C}$ \\
& pressure & 35 & $\mathrm{MPa}$ \\
\hline \multirow{2}{*}{ reheated steam parameters } & temperature & 720 & ${ }^{\circ} \mathrm{C}$ \\
& pressure & 7.4 & $\mathrm{MPa}$ \\
\hline pressure in the condenser & 5.0 & $\mathrm{kPa}$ \\
temperature of the feed water & 330 & ${ }^{\circ} \mathrm{C}$ \\
efficiency of the boiler & 94.5 & $\%$ \\
gross electric power & 900 & $\mathrm{MW}$ \\
gross power plant efficiency & 52.11 & $\%$ \\
\hline
\end{tabular}




\subsection{An Outline of the Calculation Procedure}

The initial values of decision parameters (pressures) corresponding the marked sections from Figure 2 are collected in Table 3, which also provides information about the imposed lower limits. These are the minimum pressure values required for the PP thermal cycle to obtain a convergent solution. In the calculations carried out, no upper limits were assumed because, as indicated by previous observations [40], global efficiency increases most often with an increase in bleed pressures. Nevertheless, during the optimisation procedure, the parameters of the bleed steam were controlled so that they did not exceed the water liquid-vapor critical point, which could have been undesirable. The PP gross efficiency defined as:

$$
\eta_{G E}=\frac{P_{T}}{Q_{I N}}
$$

was selected as the objective function. In the above relation, $P_{T}$ is the total power generated and $Q_{I N}$ the fuel chemical energy. It is important to note that the gross electric power was fixed at the constant level of $900 \mathrm{MW}$ during the optimisation process.

Table 3. The initial values of the decision variables, together with their lower bounds.

\begin{tabular}{cccccccccccc}
\hline Section & \multicolumn{2}{c}{ HP } & \multicolumn{2}{c}{ T-T } & IP & & LP \\
\hline $\begin{array}{c}\text { Parameter } \\
\text { Unit }\end{array}$ & $\begin{array}{c}\mathbf{p}_{\mathbf{1}} \\
{[\mathbf{M P a}]}\end{array}$ & $\begin{array}{c}\mathbf{p}_{\mathbf{2}} \\
{[\mathbf{M P a}]}\end{array}$ & $\begin{array}{c}\mathbf{p}_{\mathbf{3}} \\
{[\mathbf{M P a}]}\end{array}$ & $\begin{array}{c}\mathbf{p}_{\mathbf{4}} \\
{[\mathbf{M P a}]}\end{array}$ & $\begin{array}{c}\mathbf{p}_{\mathbf{5}} \\
{[\mathbf{M P a}]}\end{array}$ & $\begin{array}{c}\mathbf{p}_{\mathbf{6}} \\
{[\mathbf{M P a}]}\end{array}$ & $\begin{array}{c}\mathbf{p}_{\mathbf{7}} \\
{[\mathbf{M P a}]}\end{array}$ & $\begin{array}{c}\mathbf{p}_{\mathbf{8}} \\
{[\mathbf{M P a}]}\end{array}$ & $\begin{array}{c}\mathbf{p}_{\mathbf{9}} \\
{[\mathbf{M P a}]}\end{array}$ & $\begin{array}{c}\mathbf{p}_{\mathbf{1 0}} \\
{[\mathbf{M P a}]}\end{array}$ & $\begin{array}{c}\mathbf{p}_{\mathbf{1 1}} \\
{[\mathbf{M P a}]}\end{array}$ \\
\hline $\begin{array}{c}\text { initial value } \\
\text { lower bound }\end{array}$ & 13.5 & 8.0 & 4.6 & 2.4 & 1.2 & 0.5 & 0.5 & 0.26 & 0.08 & 0.02 & 0.005 \\
& 10.0 & 7.0 & 2.8 & 1.5 & 0.8 & 0.1 & 0.1 & 0.1 & 0.01 & 0.01 & 0.001 \\
\hline
\end{tabular}

\section{Results}

The presentation of the results is split into two parts. Firstly, the study of the search paths of the NM algorithm under the different algorithm setups assumed (taken from Table 1) for two decision variables only is presented. When two decision variables are analysed, it is easy to illustrate the algorithm searching path for the optimum solution. Secondly, the influence of both the number of decision variables and NM setups (also taken from Table 1) on the objective function and computing time is analysed.

\subsection{Study of the Algorithm Searching Paths}

In the present section, the analysis of the searching path of NM is analysed. In order to enable the visualisation of the searching for the local optimum, only two out of eleven decision variables were firstly considered in the optimisation procedure, namely, pressures $p_{1}$ and $p_{2}$. Four different initial starting points were selected as initial guesses. The locations of each starting point representing the simplexes' centres (marked as runs 1 to 4 ) together with the location of the local optimum are illustrated in Figure 3, whereas the exact coordinates are presented in Table 4. The selection of the proposed simplex centre locations was aimed at starting the optimisation process from different sides of the local optimum. The optimisation procedure was performed for each initial guess, as well as for each set of NM operating conditions (see Table 1). 


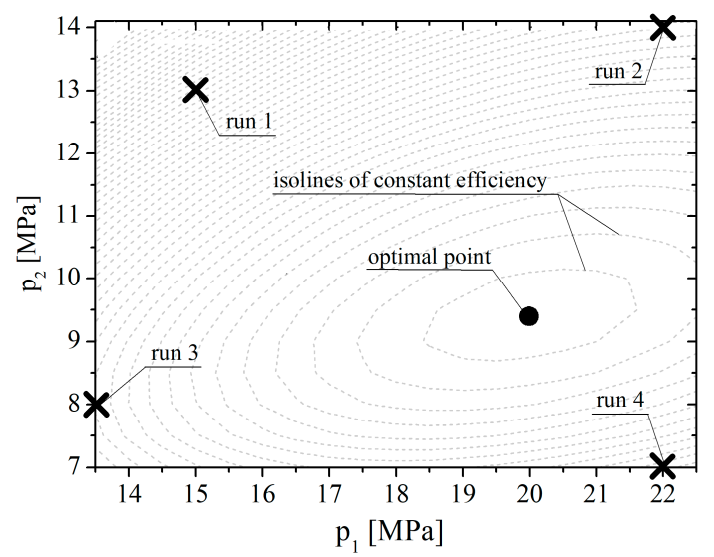

Figure 3. The location of each simplex centre for each run, together with the position of the local optimum.

Table 4. The location of the starting points (simplexes' centres) for each run, and the position of the local optimum.

\begin{tabular}{ccc}
\hline Run & $\mathbf{p}_{\mathbf{1}}$ [MPa] & $\mathbf{p}_{\mathbf{2}}$ [MPa] \\
\hline 1 & 15.0 & 13.0 \\
2 & 22.0 & 14.0 \\
3 & 13.5 & 8.0 \\
4 & 22.0 & 7.0 \\
\hline optimum & 20.0 & 9.39 \\
\hline
\end{tabular}

Figure 4a-d illustrate the paths in the design space for the various initial guesses described as runs 1 to 4 (see Table 4). Each run was realised for three different NM operating conditions, i.e., setup 1-standard NM (dark grey line with circles), setup 2-the configuration proposed by Fan and Zahara [42] (light grey line with squares) and setup 3-the algorithm setup proposed by Wang and Shoup [44] (black line with triangles). The exact values of NM coefficients are given in Table 1. The visible symbols in Figure $4 a-d$ represent the centroids of the consecutively generated simplexes. One can see that the most effective NM configuration corresponds to the one proposed by Wang and Shoup [44] (see Figure 4a,b,d). Moreover, as can be observed in Figure 4c, only the algorithm equipped with parameters from setup 3 was able to find the local optimum, whereas the searching process for the two other NM configurations was stopped far from that point.

(a)

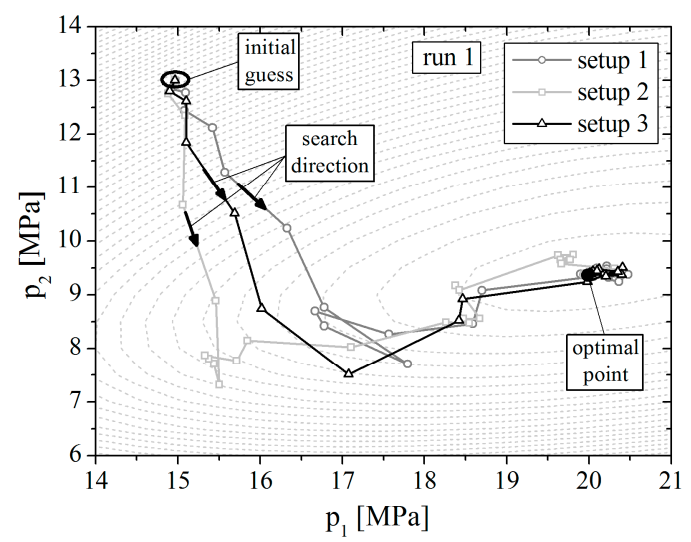

(b)

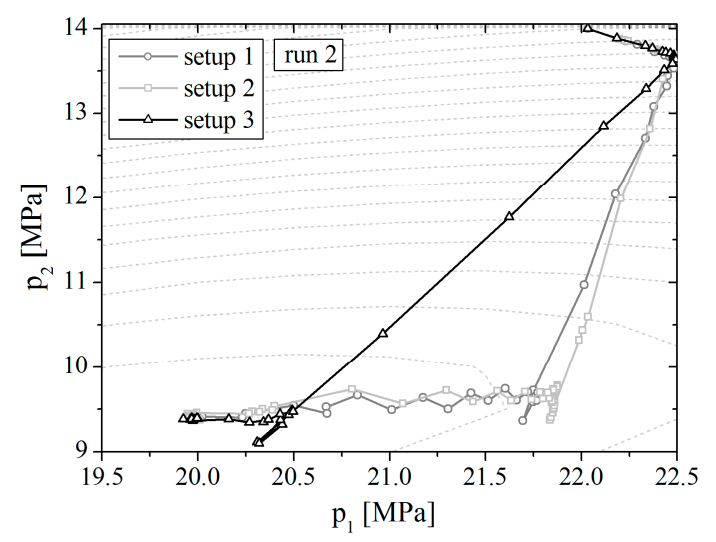

Figure 4. Cont. 
(c)

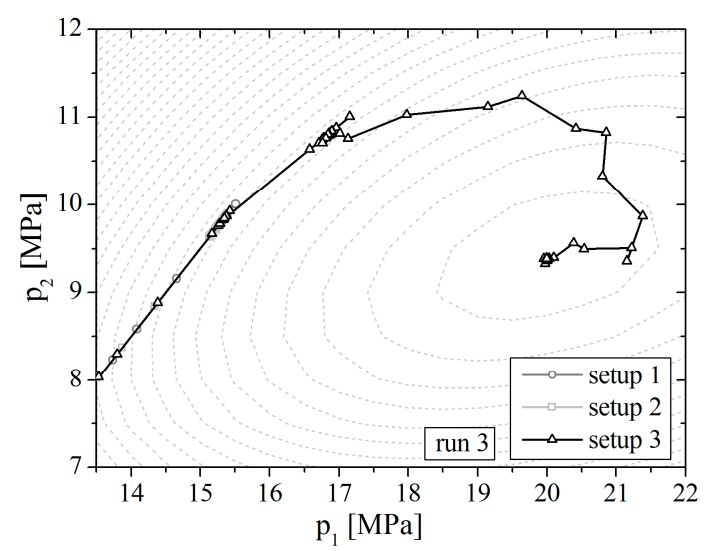

(d)

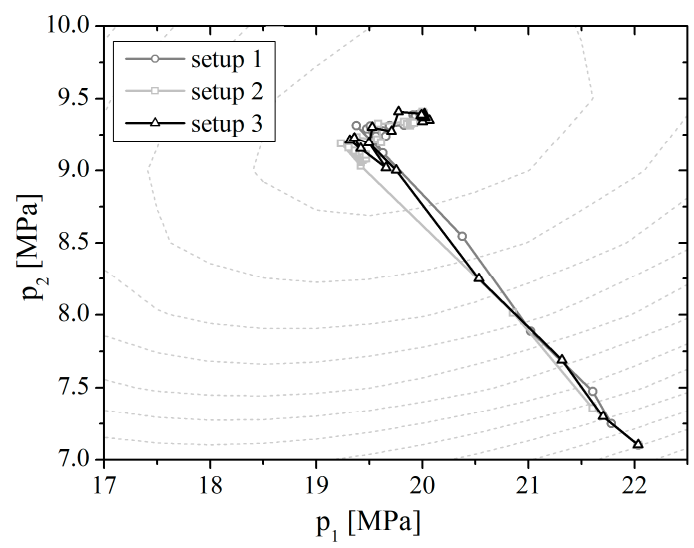

Figure 4. The evolution of the iteration procedure for three different NM operating conditions, for run 1 (a), run 2 (b), run 3 (c) and run 4 (d).

As far as the optimum point value and the associated efficiency gain are concerned, there is no difference between the three configurations of parameters, except in run 3 , where the convergence was obtained only for Wang's configuration (see Table 5).

Table 5. The numbers of steps, positions of optimal points and rise in the efficiency for each NM configuration.

\begin{tabular}{|c|c|c|c|c|c|c|c|c|c|c|c|c|}
\hline \multirow{3}{*}{ Run } & \multicolumn{3}{|c|}{ Number of Steps } & \multicolumn{6}{|c|}{ Position of Optimal Point } & \multirow{2}{*}{\multicolumn{3}{|c|}{$\begin{array}{c}\text { Efficiency Rise } \\
\text { [Percentage Points] }\end{array}$}} \\
\hline & & & & $\begin{array}{c}\mathrm{p}_{1} \\
{[\mathrm{MPa}]}\end{array}$ & $\begin{array}{c}\mathrm{p}_{2} \\
{[\mathrm{MPa}]}\end{array}$ & $\begin{array}{c}\mathrm{p}_{1} \\
{[\mathrm{MPa}]}\end{array}$ & $\begin{array}{c}\mathrm{p}_{2} \\
{[\mathrm{MPa}]}\end{array}$ & $\begin{array}{c}\mathrm{p}_{1} \\
{[\mathrm{MPa}]}\end{array}$ & $\begin{array}{c}\mathrm{p}_{2} \\
{[\mathrm{MPa}]}\end{array}$ & & & \\
\hline & Standard & Fan & Wang & \multicolumn{2}{|c|}{ Standard } & \multicolumn{2}{|c|}{ Fan } & \multicolumn{2}{|c|}{ Wang } & \multicolumn{2}{|c|}{ StandardFan } & \multirow{2}{*}{$\begin{array}{l}\text { Wang } \\
0.140\end{array}$} \\
\hline 1 & 33 & 55 & 26 & 20.0 & 9.39 & 20.0 & 9.39 & 20.0 & 9.39 & 0.140 & 0.140 & \\
\hline 2 & 47 & 86 & 39 & 20.0 & 9.38 & 20.0 & 9.38 & 20.0 & 9.39 & 0.140 & 0.140 & 0.140 \\
\hline 3 & 21 (fail) & $\begin{array}{c}36 \\
\text { (fail) }\end{array}$ & 58 & 15.3 & 9.85 & 15.3 & 9.84 & 20.0 & 9.39 & 0.045 & 0.045 & 0.140 \\
\hline 4 & 25 & 42 & 24 & 20.0 & 9.39 & 20.0 & 9.38 & 20.0 & 9.39 & 0.140 & 0.140 & 0.140 \\
\hline
\end{tabular}

\subsection{The Impact of the Decision Variable Number on PP Efficiency and Computing Time}

The already presented study clearly shows that the set of NM coefficients proposed by Wang and Shoup [44] provides the most efficient algorithm behaviour (among examined ones). However, it is interesting to show how each optimisation algorithm configuration would behave with larger numbers of decision variables. Hence, in the present sections, the influence of the number of decision variables on both the objective function and the computing time is analysed. Similarly, as in chapter 4.1, four runs were considered; however, this time, the addition decision variables were introduced in each run. The computing procedure follows the schedule given in Table 6. In each subsequent run, the bleed and outlet pressures from one additional turbine section were included. In run 3, only one additional decision variable, $p_{7}$, was considered, as there was no steam bleed in the IP section (see Figure 2).

Table 6. The groups of decision variables investigated in each run.

\begin{tabular}{|c|c|c|c|c|c|c|c|c|c|c|c|c|}
\hline \multirow{2}{*}{ Run } & \multirow{2}{*}{ Number of Decision Variables } & \multicolumn{2}{|c|}{ HP } & \multicolumn{4}{|c|}{$\mathrm{T}-\mathrm{T}$} & \multirow{2}{*}{$\begin{array}{l}\text { IP } \\
p_{7}\end{array}$} & \multicolumn{4}{|c|}{ LP } \\
\hline & & $p_{1}$ & $\mathrm{p}_{2}$ & $p_{3}$ & $\mathrm{p}_{4}$ & $\mathrm{p}_{5}$ & $\mathrm{p}_{6}$ & & $\mathrm{p}_{8}$ & $\mathrm{p}_{9}$ & $\mathrm{p}_{10}$ & $\mathrm{p}_{11}$ \\
\hline 1 & 2 & + & + & & & & & & & & & \\
\hline 2 & 6 & + & + & + & + & + & + & & & & & \\
\hline 3 & 7 & + & + & + & + & + & + & + & & & & \\
\hline 4 & 11 & + & + & + & + & + & + & + & + & + & + & + \\
\hline
\end{tabular}


It should be noted that calculations performed for a single initial simplex configuration (position and orientation) may not be representative of other simplex configurations. That is why the computations were performed ten times for each run, with different positions and orientations of the initial simplex.

The optimal efficiencies for each run and for each NM setup, along with its reference value (corresponding to the reference PP cycle; see Sections 3.1 and 3.2), are shown in Figure 5a. It should be noted that each bar consists of two parts, i.e., uniformly filled and dashed parts related to the minimal and maximal efficiency achieved in the optimisation for different simplexes' configurations. The corresponding quantitative results, in the form of the gain of efficiency with respect to the reference value, are given in Table 7 . In the first run, the bleed and the outlet pressures from HP turbine sections were considered. The optimisation of this part led to an increase in efficiency by 0.14 percentage points, and the NM configuration with the coefficients from setup 3 appeared to be the best choice (among examined sets). In run 2 (when the pressures related to T-T were included), an efficiency increase by about 0.35 percentage points, with negligible variation for each NM setup, can be observed. A slight increase in efficiency (when comparing to run 2) of up to approximately 0.38 percentage points in run 3 (with additional outlet pressure from the IP turbine) can be noted. Similarly, a minor variation in optimised efficiency in each NM configuration is visible. A noticeable rise in efficiency of up to about 0.9 percentage points was achieved in run 4 , when the LP section is taken into account. Here, the largest variation in optimised efficiency can be observed, which confirms the advantage of setup 3 over the two other NM configurations (see Figure 5a).

(a)

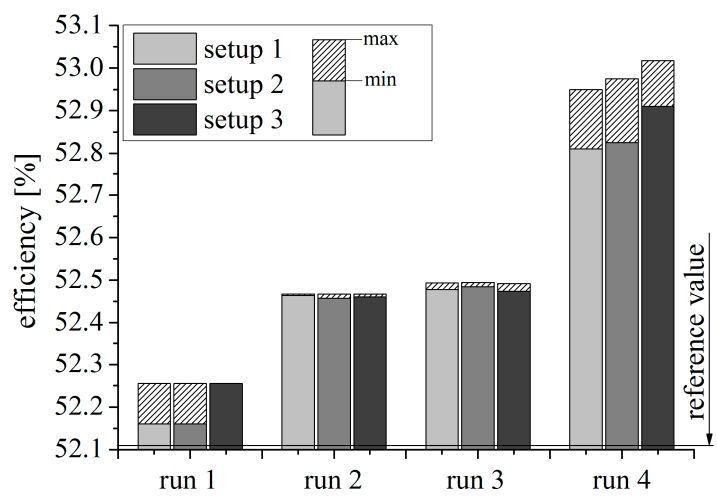

(b)

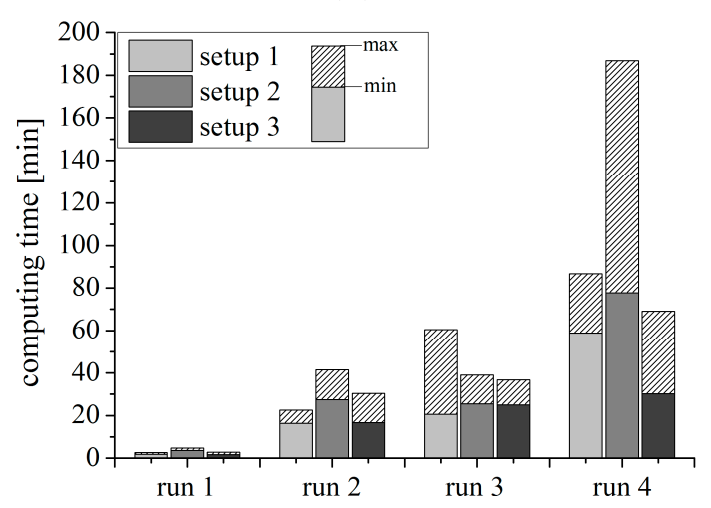

Figure 5. The optimised PP efficiency (a) and computing time (b) for each run and NM setup.

Table 7. The efficiency rise in each run and for each NM setup.

\begin{tabular}{ccccc}
\hline \multirow{2}{*}{ NM Configuration } & Run 1 & Run 2 & Run 3 & Run 4 \\
\cline { 2 - 5 } & \multicolumn{4}{c}{ Range of Efficiency Rise [Percentage Points] } \\
\hline Setup 1 & $0.045-0.140$ & $0.349-0.352$ & $0.363-0.378$ & $0.695-0.834$ \\
Setup 2 & $0.045-0.140$ & $0.342-0.352$ & $0.369-0.379$ & $0.699-0.849$ \\
Setup 3 & 0.140 & $0.345-0.352$ & $0.359-0.376$ & $0.795-0.902$ \\
\hline
\end{tabular}

Another important parameter for characterising any optimisation algorithm is the CT required to achieve a convergent solution. The present simulations were conducted using a personal computer with a $2 \times 2.21 \mathrm{GHz}$ processor. The standard function available in MATLAB was used to calculate the computing time, which included the calculation of all of the thermal cycle parameters in IPSEpro and the NM-based optimisation procedure in MATLAB.

The calculated values of CT determined for each run and for each NM configuration are presented in Figure 5b, whereas the corresponding quantitative data are presented in Table 8 (which also include the averaged values of CT). Similarly, as in the case of efficiency, the minimal and the maximal computing times recorded were distinguished. According to the results from Figure $5 b$, the progressive 
increase in the computing time with each subsequent run can be observed (i.e., with a growing number of decision variables). However, as the individual values of computing time and their variations change significantly for each NM configuration, a more detailed discussion should be given. Similar values of minimal CT were recorded in runs 1 and 2 for setups 1 and 3; however, setup 1 has an advantage over setup 3, as the variation of CT is smaller. In run 3, the smallest and the highest CTs were recorded for setup 1. In the fourth run, both the smallest minimal and maximal values of CT were recorded for setup 3. In order to assess which configuration ensures the smallest CT, its averaged values were collected and are presented in Table 8 . As can be seen, setup 3 ensures the smallest averaged CT in runs 1, 3 and 4-whereas in run 2, setup 1 has a slight advantage over run 3.

Table 8. The computing time in each run and for each NM setup.

\begin{tabular}{|c|c|c|c|c|c|c|c|c|}
\hline \multirow{3}{*}{$\begin{array}{c}\mathrm{NM} \\
\text { Configuration }\end{array}$} & \multicolumn{2}{|c|}{ Run 1} & \multicolumn{2}{|c|}{ Run 2} & \multicolumn{2}{|c|}{ Run 3} & \multicolumn{2}{|c|}{ Run 4} \\
\hline & \multicolumn{8}{|c|}{ Computing Time [min] } \\
\hline & Min-Max & Averaged & Min-Max & Averaged & Min-Max & Averaged & Min-Max & Averaged \\
\hline Setup 1 & $1.9-0.8$ & 2.3 & $16.4-6.2$ & 19.5 & $20.6-39.8$ & 40.5 & $58.8-28.0$ & 72.8 \\
\hline Setup 2 & $3.7-1.1$ & 4.3 & $27.4-14.2$ & 34.5 & $25.5-13.6$ & 32.3 & $77.8-109.1$ & 132.3 \\
\hline Setup 3 & $1.6-1.2$ & 2.2 & $16.7-13.6$ & 23.5 & $25.1-11.7$ & 30.9 & $30.3-38.8$ & 49.7 \\
\hline
\end{tabular}

\subsection{Discussion About the Efficiency Increase}

The application of the optimisation procedure allowed for achieving an efficiency increase as high as 0.9 percentage points in comparison to the reference case. A gain in efficiency of up to 0.14 percentage points was obtained in run 1. Such an increase in PP efficiency can be explained by the growth in pressures $\mathrm{p}_{1}$ and $\mathrm{p}_{2}$ (see Table 9), and the resulting rise in corresponding temperatures. As a consequence, the HP preheating section transfers more heat, and the temperature of the feedwater at the boiler inlet increases together with the PP efficiency. One should note that cold reheat pressure, $\mathrm{p}_{2}$, increases from $8.0 \mathrm{MPa}$ (reference value) to $11.79 \mathrm{MPa}$. This change in pressure affects both the tuning turbine characteristics and the reheat section.

As for deaerator pressure, $\mathrm{p}_{4}$, according to [57], a higher pressure will have a major impact on the deaerator working conditions. Consequently, it will also have an impact on the feedwater tank. However, the determined value of the deaerator pressure leads to a decrease in pumping power requirements due to a smaller pressure ratio of the feedwater pump.

The remaining pressures $\mathrm{p}_{5}-\mathrm{p}_{11}$ correspond to the T-T and LP bleed sections responsible for feeding the IP and LP preheating sections. Increases in these pressures lead to an increase in the temperature of the medium, and in turn, a rise in PP efficiency.

Table 9. The optimised pressure values collected from the case with the highest efficiency gained.

\begin{tabular}{cccccccccccc}
\hline Section & \multicolumn{2}{c}{ HP } & \multicolumn{3}{c}{ T-T } & \multicolumn{1}{c}{ IP } & \multicolumn{3}{c}{ LP } \\
\hline $\begin{array}{c}\text { Parameter } \\
\text { Unit }\end{array}$ & $\begin{array}{c}\mathbf{p}_{\mathbf{1}} \\
{[\mathbf{M P a}]}\end{array}$ & $\begin{array}{c}\mathbf{p}_{\mathbf{2}} \\
{[\mathbf{M P a}]}\end{array}$ & $\begin{array}{c}\mathbf{p}_{\mathbf{3}} \\
{[\mathbf{M P a}]}\end{array}$ & $\begin{array}{c}\mathbf{p}_{\mathbf{4}} \\
{[\mathbf{M P a}]}\end{array}$ & $\begin{array}{c}\mathbf{p}_{\mathbf{5}} \\
{[\mathbf{M P a}]}\end{array}$ & $\begin{array}{c}\mathbf{p}_{\mathbf{6}} \\
{[\mathbf{M P a}]}\end{array}$ & $\begin{array}{c}\mathbf{p}_{\mathbf{7}} \\
{[\mathbf{M P a}]}\end{array}$ & $\begin{array}{c}\mathbf{p}_{\mathbf{8}} \\
{[\mathbf{M P a}]}\end{array}$ & $\begin{array}{c}\mathbf{p}_{\mathbf{9}} \\
{[\mathbf{M P a}]}\end{array}$ & $\begin{array}{c}\mathbf{p}_{\mathbf{1 0}} \\
{[\mathbf{M P a}]}\end{array}$ & $\begin{array}{c}\mathbf{p}_{\mathbf{1 1}} \\
{[\mathbf{M P a}]}\end{array}$ \\
\hline $\begin{array}{c}\text { initial value } \\
\text { optimised value }\end{array}$ & 13.5 & 8.0 & 4.6 & 2.4 & 1.2 & 0.5 & 0.5 & 0.26 & 0.08 & 0.02 & 0.005 \\
\hline
\end{tabular}

\section{Conclusions}

This work demonstrates how IPSEpro, MATLAB and MS Excel can be effectively combined for the optimisation process for complex power plants. The NM algorithm was employed as one of the most frequently used direct search approaches. Particular attention was devoted to the studying of different NM operating coefficients, i.e., reflection, expansion, contraction and simplex size. Three different sets of NM coefficients were investigated, all adopted from the available literature (a standard NM setup, the setup of Fan and Zahara [42] and the setup proposed by Wang and Shoup [44]). The selection of 
the most suitable NM configuration (among these offered in the literature) was performed based on both $\mathrm{CT}$ and the capability of the algorithm in finding the PP configuration ensuring an efficiency rise.

Where a small number of decision variables was concerned (pressures $p_{1}$ and $p_{2}$ ), no difference between the three investigated configurations was observed; however, the standard setup and the one proposed by Fan and Zahara [42] failed in finding optimal solutions in one out of four investigated simplex configurations.

When a greater number of decision variables was taken into account, the setup of Wang and Shoup [44] allowed finding the PP configuration with the highest efficiency. Moreover, the variation of the optimised objective function was the smallest, regardless of simplex configurations. It was also found that the CT required to reach a convergent solution for this NM configuration is the shortest of those from the three investigated algorithm setups. This observation shows that this configuration, tested previously on seven simple test functions, also works well with a complex optimisation task and can be recommended as the most advisable one (among the ones available in the literature).

Finally, the optimisation procedure allowed achieving a total increase of efficiency equal to 0.9 percentage points compared with the reference value, and this should be regarded as a substantial improvement, proving that the proposed integrated numerical package is a useful and effective tool in the optimisation of complex thermal cycles.

Author Contributions: Conceptualization, W.E., P.N. and M.M.; methodology, Ł.K., M.M.; software, Ł.K. and M.M.; formal analysis, P.N, W.E.; writing-original draft preparation, P.N.; writing-review and editing, W.E. and M.M.; supervision, W.E.; Funding Acquisition, W.E. All authors have read and agreed to the published version of the manuscript.

Funding: This research was funded by Polish Ministry of Science and Higher Education, statutory funds, grant number BS/PB-1-103-310/2020/P and by National Centre of Science grant number DEC-2013/09/N/ST8/02105.

Conflicts of Interest: The authors declare no conflict of interest.

\section{References}

1. Oko, E.; Wang, M. Dynamic modelling, validation and analysis of coal-fired subcritical power plant. Fuel 2014, 135, 292-300. [CrossRef]

2. Zhang, D. Ultra-Supercritical Coal Power Plants: Materials, Technologies and Optimisation; Elsevier: Amsterdam, The Netherlands, 2013; pp. 1-20.

3. Elsner, W.; Kowalczyk, Ł.; Niegodajew, P.; Drobniak, S. Thermodynamic Analysis of a Thermal Cycle of Supercritical Power Plant. Mech. Mech. Eng. 2011, 3, 129-137.

4. Wang, G.-L.; Yan, W.-W.; Chen, S.-H.; Zhang, X.; Shao, H.-H. Multivariable constrained predictive control of main steam temperature in ultra-supercritical coal-fired power unit. J. Energy Inst. 2015, 88, $181-187$. [CrossRef]

5. Stępczyńska, K.; Kowalczyk, Ł.; Dykas, S.; Elsner, W. Calculation of a $900 \mathrm{MW}$ conceptual 700/720 ${ }^{\circ} \mathrm{C}$ coal-fired power unit with an auxiliary extraction-backpressure turbine. J. Power Technol. 2012, 92, $266-273$.

6. Muramatsu, S.; Miyakawa, K.; Onoda, M.; Takahashi, K.; Iwashige, K. Completion of a 1120-MVA Turbine Generator for Huadian International Zouxian Power Plant in China. Hitachi Rev. 2005, 56, 99-103.

7. Jang, H.J.; Kang, S.Y.; Lee, J.J.; Kim, T.S.; Park, S.J. Performance analysis of a multi-stage ultra-supercritical steam turbine using computational fluid dynamics. Appl. Therm. Eng. 2015, 87, 352-361. [CrossRef]

8. Pavan, A.H.V.; Vikrant, K.S.N.; Ravibharath, R.; Singh, K. Development and evaluation of SUS 304H-IN 617 welds for advanced ultra supercritical boiler applications. Mater. Sci. Eng. A 2015, 642, 32-41. [CrossRef]

9. Kolehmainen, J.; Elfvengren, J.; Saarenrinne, P. measurement-integrated solution for particle image velocimetry and volume fraction measurements in a fluidized bed. Int. J. Multiph. Flow 2013, 56, 72-80. [CrossRef]

10. Blaszczuk, A.; Leszczynski, J.; Nowak, W. Simulation model of the mass balance in a supercritical circulating fluidized bed combustor. Powder Technol. 2013, 246, 317-326. [CrossRef]

11. Wang, L.; Yang, D.; Shen, Z.; Mao, K.; Long, J. Thermal-hydraulic calculation and analysis of a $600 \mathrm{MW}$ supercritical circulating fluidized bed boiler with annular furnace. Appl. Therm. Eng. 2016, 95, 42-52. [CrossRef]

12. Łukowicz, H.; Dykas, S.; Rulik, S.; Steppzyńska, K. Thermodynamic and economic analysis of a $900 \mathrm{MW}$ ultra-supercritical power unit. Arch. Thermodyn. 2011, 32, 231-244. [CrossRef] 
13. Xu, G.; Xu, C.; Yang, Y.; Fang, Y.; Zhou, L.; Yang, Z. Thermodynamic and economic analysis of a partially-underground tower-type boiler design for advanced double reheat power plants. Appl. Therm. Eng. 2015, 78, 565-575. [CrossRef]

14. Xu, G.; Zhou, L.; Zhao, S.; Liang, F.; Xu, C.; Yang, Y. Optimum superheat utilization of extraction steam in double reheat ultra-supercritical power plants. Appl. Energy 2015, 160, 863-872. [CrossRef]

15. Ziółkowski, P.; Kowalczyk, T.; Kornet, S.; Badur, J. On low-grade waste heat utilization from a supercritical steam power plant using an ORC-bottoming cycle coupled with two sources of heat. Energy Convers. Manag. 2017, 146, 158-173. [CrossRef]

16. Ziółkowski, P.; Badur, J.; Ziółkowski, P.J. An energetic analysis of a gas turbine with regenerative heating using turbine extraction at intermediate pressure-Brayton cycle advanced according to Szewalski's idea. Energy 2019, 185, 763-786.

17. Kotowicz, J.; Job, M.; Brzeczek, M. The characteristics of ultramodern combined cycle power plants. Energy 2015, 92, 197-211. [CrossRef]

18. Ryzhkov, A.; Bogatova, T.; Gordeev, S. Technological solutions for an advanced IGCC plant. Fuel 2018, 214, 63-72. [CrossRef]

19. Stępczyńska-Drygas, K.; Łukowicz, H.; Dykas, S. Calculation of an advanced ultra-supercritical power unit with CO2 capture installation. Energy Convers. Manag. 2013, 74, 201-208. [CrossRef]

20. Rao, S.S. Engineering Optimization Theory and Practice; John Wiley \& Sons: Hoboken, NJ, USA, 1996.

21. Piotrowski, A.P. Regarding the rankings of optimization heuristics based on artificially-constructed benchmark functions. Inf. Sci. (Ny) 2015, 297, 191-201. [CrossRef]

22. Kler, A.M.; Zharkov, P.S.; Epishkin, N.O. Parametric optimization of supercritical power plants using gradient methods. Energy 2019, 116230. [CrossRef]

23. Kolda, T.G.; Lewis, R.M.; Torczon, V. Optimization by Direct Search: New Perspectives on Some Classical and Modern Methods. SIAM Rev. 2003, 45, 385-482. [CrossRef]

24. Baños, R.; Manzano-Agugliaro, F.; Montoya, F.G.; Gil, C.; Alcayde, A.; Gómez, J. Optimization methods applied to renewable and sustainable energy: A review. Renew. Sustain. Energy Rev. 2011, 15, 1753-1766. [CrossRef]

25. Hajabdollahi, F.; Hajabdollahi, Z.; Hajabdollahi, H. Soft computing based multi-objective optimization of steam cycle power plant using NSGA-II and ANN. Appl. Soft Comput. 2012, 12, 3648-3655. [CrossRef]

26. Kaviri, A.G.; Jafar, M.N.M.; Tholudin, M.L.; Avval, H.B. Thermodynamic modeling and exergoeconomic optimization of a steam power plant using a genetic algorithm. Nternational J. Chem. Environ. Eng. 2011, 2, 377-383.

27. Martelli, E.; Amaldi, E.; Consonni, S. Numerical optimization of heat recovery steam cycles: Mathematical model, two-stage algorithm and applications. Comput. Chem. Eng. 2011, 35, 2799-2823. [CrossRef]

28. Chaibakhsh, A.; Ghaffari, A. Steam turbine model. Simul. Model. Pract. Theory 2008, 16, 1145-1162. [CrossRef]

29. Ehyaei, M.A.; Tahani, M.; Ahmadi, P.; Esfandiari, M. Optimization of fog inlet air cooling system for combined cycle power plants using genetic algorithm. Appl. Therm. Eng. 2015, 76, 449-461. [CrossRef]

30. Gen, M.; Yun, Y. Reliab. Soft computing approach for reliability optimization: State-of-the-art survey. Eng. Syst. Saf. 2006, 91, 1008-1026. [CrossRef]

31. Bertini, I.; de Felice, M.; Pannicelli, A.; Pizzuti, S. Soft computing based optimization of combined cycled power plant start-up operation with fitness approximation methods. Appl. Soft Comput. 2011, 11, 4110-4116. [CrossRef]

32. Sanpasertparnich, T.; Aroonwilas, A. Simulation and optimization of coal-fired power plants. Energy Procedia 2009, 1, 3851-3858. [CrossRef]

33. Espatolero, S.; Romeo, L.M.; Cortés, C. Efficiency improvement strategies for the feedwater heaters network designing in supercritical coal-fired power plants. Appl. Therm. Eng. 2014, 73, 449-460. [CrossRef]

34. Chagnon-Lessard, N.; Mathieu-Potvin, F.; Gosselin, L. Optimal design of geothermal power plants: A comparison of single-pressure and dual-pressure organic Rankine cycles. Geothermics 2020, 86, 101787. [CrossRef]

35. Chagnon-Lessard, N.; Copeland, C.; Mathieu-Potvin, F.; Gosselin, L. Maximizing specific work output extracted from engine exhaust with novel inverted Brayton cycles over a large range of operating conditions. Energy 2020, 191, 116350. [CrossRef] 
36. Wang, L.; Yang, Y.; Dong, C.; Morosuk, T.; Tsatsaronis, G. Multi-objective optimization of coal-fired power plants using differential evolution. Appl. Energy 2014, 115, 254-264. [CrossRef]

37. Chagnon-Lessard, N.; Mathieu-Potvin, F.; Gosselin, L. Geothermal power plants with maximized specific power output: Optimal working fluid and operating conditions of subcritical and transcritical Organic Rankine Cycles. Geothermics 2016, 64, 111-124. [CrossRef]

38. Fukushima, I.; Hino, S.; Nakamoto, M.; Takamiya, S. Improved Combined Cycle Power Plant Operation Design Using Optimization Method. Electr. Eng. Japan 1992, 112, 1057-1064. [CrossRef]

39. Kowalczyk, Ł.; Elsner, W. Comparative analysis of optimisation methods applied to thermal cycle of a coal fired power plant. Arch. Thermodyn. 2013, 34, 175-186. [CrossRef]

40. Kowalczyk, Ł.; Elsner, W.; Niegodajew, P.; Marek, M. Gradient-free methods applied to optimisation of advanced ultra-supercritical power plant. Appl. Therm. Eng. 2016, 96, 200-208. [CrossRef]

41. Gao, F.; Han, L. Implementing the Nelder-Mead simplex algorithm with adaptive parameters. Comput. Optim. Appl. 2012, 51, 259-277. [CrossRef]

42. Fan, S.-K.S.; Zahara, E. A hybrid simplex search and particle swarm optimization for unconstrained optimization. Eur. J. Oper. Res. 2007, 181, 527-548. [CrossRef]

43. Begambre, O.; Laier, J.E. A hybrid Particle Swarm Optimization—Simplex algorithm (PSOS) for structural damage identification. Adv. Eng. Softw. 2009, 40, 883-891. [CrossRef]

44. Wang, P.C.; Shoup, T.E. Parameter sensitivity study of the Nelder-Mead Simplex Method. Adv. Eng. Softw. 2011, 42, 529-533. [CrossRef]

45. Schuster, A.; Karellas, S.; Kakaras, E.; Spliethoff, H. Energetic and economic investigation of Organic Rankine Cycle applications. Appl. Therm. Eng. 2009, 29, 1809-1817. [CrossRef]

46. Doukelis, A.; Vorrias, I.; Grammelis, P.; Kakaras, E.; Whitehouse, M.; Riley, G. Partial O2-fired coal power plant with post-combustion $\mathrm{CO} 2$ capture: A retrofitting option for $\mathrm{CO} 2$ capture ready plants. Fuel 2009, 88, 2428-2436. [CrossRef]

47. Pires, T.S.; Cruz, M.E.; Colaço, M.J. Response surface method applied to the thermoeconomic optimization of a complex cogeneration system modeled in a process simulator. Energy 2013, 52, 44-54. [CrossRef]

48. Elsner, W.; Wysocki, M.; Niegodajew, P.; Borecki, R. Experimental and economic study of small-scale CHP installation equipped with downdraft gasifier and internal combustion engine. Appl. Energy 2017, 202, 213-227. [CrossRef]

49. Nelder, J.A.; Mead, R. A simplex method for function minimization. Comput. J. 1965, 7, 308-313. [CrossRef]

50. Chang, K.-H. Stochastic Nelder-Mead simplex method-A new globally convergent direct search method for simulation optimization. Eur. J. Oper. Res. 2012, 220, 684-694. [CrossRef]

51. Luchi, F.; Krohling, R.A. Differential Evolution and Nelder-mead for Constrained Non-linear Integer Optimization Problems. Procedia Comput. Sci. 2015, 55, 668-677. [CrossRef]

52. Hooshmand, R.-A.; Parastegari, M.; Morshed, M.J. Emission, reserve and economic load dispatch problem with non-smooth and non-convex cost functions using the hybrid bacterial foraging-Nelder-Mead algorithm. Appl. Energy 2012, 89, 443-453. [CrossRef]

53. Rajan, A.; Malakar, T. Optimal reactive power dispatch using hybrid Nelder-Mead simplex based firefly algorithm. Int. J. Electr. Power Energy Syst. 2015, 66, 9-24. [CrossRef]

54. Kjaer, S.; Drinhaus, F. A modified double reheat cycle. In Proceedings of the ASME 2010 Power Conference, Chicago, IL, USA, 24 December 2010.

55. Elsner, W.; Kowalczyk, Ł.; Marek, M. Numerical thermodynamic optimization of supercritical coal fired power plant with support of IPSEpro software. Arch. Thermodyn. 2012, 33, 101-110. [CrossRef]

56. Aljundi, I.H. Energy and exergy analysis of a steam power plant in Jordan. Appl. Therm. Eng. 2009, 29, 324-328. [CrossRef]

57. Srinivas, T. Study of a deaerator location in triple-pressure reheat combined power cycle. Energy 2009, 34, 1364-1371. [CrossRef]

(C) 2020 by the authors. Licensee MDPI, Basel, Switzerland. This article is an open access article distributed under the terms and conditions of the Creative Commons Attribution (CC BY) license (http://creativecommons.org/licenses/by/4.0/). 